International Journal of Engineering \& Technology, $7(3.29)(2018) 236-242$
SPC
Website $: \frac{w w \text {. sciencepubco.com/index.php/IJET }}{\text { Research paper }}$

\title{
Investigation of base flow for an axisymmetric suddenly expanded nozzle with micro JET
}

\author{
Zakir Ilahi Chaudhary ${ }^{1 *}$, Vilas B. Shinde ${ }^{2}$, S. A. Khan ${ }^{3}$ \\ ${ }^{1}$ Dept. of Automobile Engineering Dept., M H S S College of Engineering, Mumbai, India \\ ${ }^{2}$ NHITM, Department of Mechanical Engineering, DMCE, Airoli, Navi Mumbai, Maharashtra, India \\ ${ }^{3}$ Mechanical Engineering Dept., Faculty of Engineering, IIUM, Kuala Lumpur, Malaysia \\ *Corresponding author E-mail: sakhan@iium.edu.my
}

\begin{abstract}
This investigation presents the outcome of the tests conducted to control the pressure in the re-circulation zone. Also, the efficiency of the flow controllers to govern the pressure at the base in a rapidly expanded pipe has been investigated. Tiny jets our in number of $1 \mathrm{~mm}$ diameter are positioned at the interval of 90 degrees at $6.5 \mathrm{~mm}$ from the central axis of the main jet. The Mach numbers of the abruptly expanded flows studied for base pressure range from 1.1 to 3 and the obtained wall pressure distribution is depicted for Mach number 1.6 and 1.8 respectively. Axi-symmetric round brass tubes were used to join jets; and cross-sectional area of those tubes are 2.56 . L/D ratio of the broadened pipe was differed from 1 to 10 and NPR was shifted from 3 to 11 . Notwithstanding, the outcomes displayed were for Low L/D values of 4, 3, 2 and 1 individually. Also, when the stream was released to the pipes of the given area ratios, it stayed connected with the channel divider for all the inertial levels and the NPRs tried in the present case. Further it is understood that level of expansion assumes a noteworthy part to choose the pressure at the base and its control adequacy. At whatever point, the stream is over expanded, it leads to the formation of an oblique shock at the nozzle lip, prompting improvement of the pressure in the base locale. Shock waves formation, reflection and recombination proceeded till the pressure winds up noticeably environmental and seen that the stream stays intact for low L/D ratio of 4 . Very small scale (micro) jets proved to fit in as controllers for the base pressure.
\end{abstract}

Keywords: Flow; Control; L/D Ratio; NPR; Nozzle Flow; Pressure

\section{Introduction}

The Convergent Divergent (CD) nozzle is a noteworthy design arrangement inside a jet propulsion framework that assumes an indispensable part for a vehicle working under supersonic conditions. The profile of the nozzle is important for designing a nozzle setup for aerospace vehicles flying at higher Mach numbers to limit base drag and expand the fumes gas supersonically to augment its potential. Execution of the vehicle predominately relies on upon the setup of the divergent area, which guarantees that the heading of the escaped gases is in reverse direction, as any sideways parts would not add to thrust (Ekanayake, 2013). The gas expansion through a CD nozzle from subsonic to supersonic conditions, the flow encounters many distinct physical interactions which increases kinetic energy including flow separation, flow unsteadiness, flow blending, Shock Induced Boundary Layer separation and Mach shock Diamonds (M Buoni, D Dietz, K Aslam, \& VV Subramaniam, 2001; M Buoni, D Dietz, K Aslam, \& V Subramaniam, 2001; Dutton, Herrin, Molezzi, Mathur, \& Smith, 1995). Some of these interactions may prompt to pressure loss; accordingly lessen the entire thrust created by the nozzle. Moreover, when nozzle flow is under over-expansion or under expansion, the thrust loss because of Mach shock Diamonds makes it ineffective (Lipfert \& Fruchtman, 1972). Previous examinations have demonstrated that flow phenomena happening inside (shocks and flow separations) and outside (Mach shock Diamonds) to the nozzle still result in performance downsides and are still challenging (Mates \& Settles, 2005; McLellan, 2006). For achieving its working potential, the exhaust nozzle design caters two major functions. In the first place, nozzle section configurations are varied to achieve control over propulsive system back pressure to attain perfect design conditions. Second, the design converts potential energy of the expanding gas to kinetic energy by accelerating the exhaust gas, which accomplished by efficiently expanding the gases to the ambient pressure (Gamble, Terrell, \& DeFrancesco, 2004). S. Brinkhorst et al (Brinkhorst, von Lavante, \& Wendt, 2017) investigated the choked flow condition in Venturi nozzles with cavities. Shock wave as well as the turbulent boundary layer collaborations happen in a wide range of aerospace devices, for example, supersonic wind tunnel diffusers, supersonic inlet diffusers, inlet/combustor isolators, supersonic ejectors, and shock tubes (Hyde, Escher, \& Roddy, 2003; Ikaza, 2000; Sutton \& Biblarz, 2016). It is generally identified with the system efficiency or performance in terms of total pressure loss, flow instability, and other uniquely required controls. Many flow devices frequently require a proper control of the Shock wave-boundary layer communication to fill the outline need. The stream is decelerated through a progression of shocks. All the interactions linking the boundary layer and the shock wave that builds the stagnation pressure losses. Wu and New (Wu \& New, 2017) studied the high speed jets coming out from bevelled nozzles with divergence angles of 3 and 6 degrees at Mach 1.5. The matching of Numerical and results are good, where the shape of the shock wave was either in the form of triangle and rectangle. They are not like diamond shock which are normally produced by the circular nozzle. Moreover, the shear layer exiting from the nozzle will go through the process of deflection due the pressure relaxation for short and long lip area. The jet exhaust deflects in the 
direction of the large and small nozzle lip regions under the influence of adverse and favourable pressure gradient.

For the improvement of system efficiency, different techniques can be utilized to control and to alleviate the negative impacts of base flow (Fig. 1).

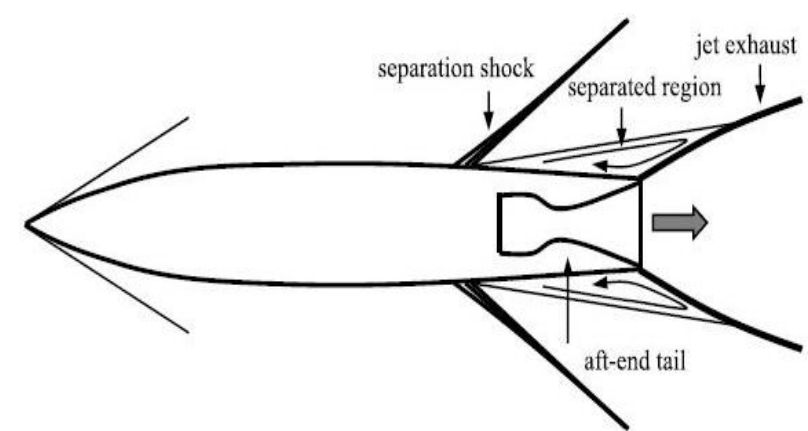

Fig. 1: Schematic of the Flow Interaction between the Free Stream Flow and the Jet Exhaust around the Aft-End of the Missile/Launcher Tail (Koppenwallner, Rammenzweig, \& Strunck, 1981).

Several theories focused on improving the base pressure and deflating negative effects caused due to free stream-exhaust interaction by altering wake flow field (Viswanath, 1996). The control methods used were both active and passive. (Tripathi, Manisankar, \& Verma, 2015; Viswanath, 1996). At transonic speeds, the boat-tail drag offsets the decrease in base drag. (Liang \& Fu, 1991) studied the base drag reduction by passive methods. Later, Hsiung and Chow found that using a cavity with compartments through splitters underneath the porous wall increases the drag reduction efficiency (Hsiung \& Chow, 1995). (Ibrahim \& Filippone, 2007) studied the base flows for optimum porous media. (Chaudhuri \& Hadjadj, 2016) carried out experiments to investigate the shock induced transient flow through a planar nozzle mimicking a shock tube experimental setup at shock Mach number Ms $=1.86$. It is observed that the initial flow-field greatly affected by the separation point and the resulting oblique shock structure. Next big task is to decrease base pressure fluctuations using the above discussed control methods. These fluctuations are related with turbulent separated flow often and also to alleviate the dynamic loading of missile's nozzle structure (Deprés, Reijasse, \& Dussauge, 2004).

The recent design of aerospace vehicles will be greatly influenced by the existing dynamic flow control at our disposal for jet inlet and exhaust systems, lifting surfaces including high-lift devices, thrus monitoring, cavity flow/acoustics, impingement jet noise reduction, and propulsion devices such as jet engines and rockets (El-Alti, 2012; Jahanmiri, 2010; King, 2010; Washburn, Gorton, \& Anders, 2002).

The experimental investigation to regulate the flow in the separated area by tiny jets by Khan and Rathakrishnan (Sher Khan \& Rathakrishnan, 2002; S. A. Khan \& Rathakrishnan, 2004). Mousavi and Roohi (Mousavi \& Roohi, 2014) carried out 3-D CFD analysis to assess the formation of shock train in case of compressible flow passed a C-D nozzle to evaluate the number of shocks, the location, and their behavior. From their study they found that RSM turbulence model is capable of predicting the authentic location of the shock waves and they agree well with the experimental results. The results also indicated the trend of the shock train in the C-D nozzle from the numerical simulation and Weiss et al. experiment. McNally et al (McNally et al., 2015) investigated the active flow control on a flat-back ground vehicle model, for aerodynamic drag reduction by employing small scale, steady jets (micro jets). Sundararaj et al (Sundararaj, Yuvaraj, Gopinath, \& Elangovan, 2014) investigated the Passive control methods like protruding ribs in the control of suddenly expanding flows. From the computational analysis for the suddenly expanded axisymmetric flows, passive controls in the form of annular ribs have been found to reduce the base pressure significantly, compared to without control. Khan et al. (Bashir, Baig, Ismail, \& Khan; Chaudhary, Shinde, Bashir, \& Khan, 2017; S Khan, Bashir, \& Asadullah, 2016) did experimental examination to study efficacy of the mechanism assess the effectiveness of the tiny jets.

The present work is mainly concerned with air jets expanding into ducts with dynamic control with tiny-jets. The nozzle proportion ratio (NPR), the Mach number, and L/D ratio were dealt as independent parameters.

\section{Experimental facility}

The analyses were completed utilizing the test set up shown in fig 2 at the Supersonic Aerodynamics Research Laboratory (HSAL), Mangalore Institute of Technology. Figure explains nozzle exit houses eight holes out of which four (marked c) were used to blow and rest for base pressure measurement. Marked holes help to control base pressure by the process of blowing and utilizing the pressure from pressure regulating tank by engaging a tube interfacing to the tank and pressure gaps (c). Pressure taps and instrumentation were same as in case of Ref. [2017].

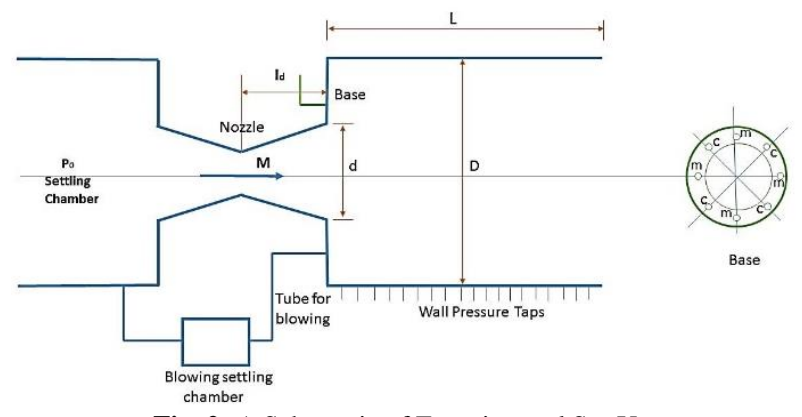

Fig. 2: A Schematic of Experimental Set-Up.

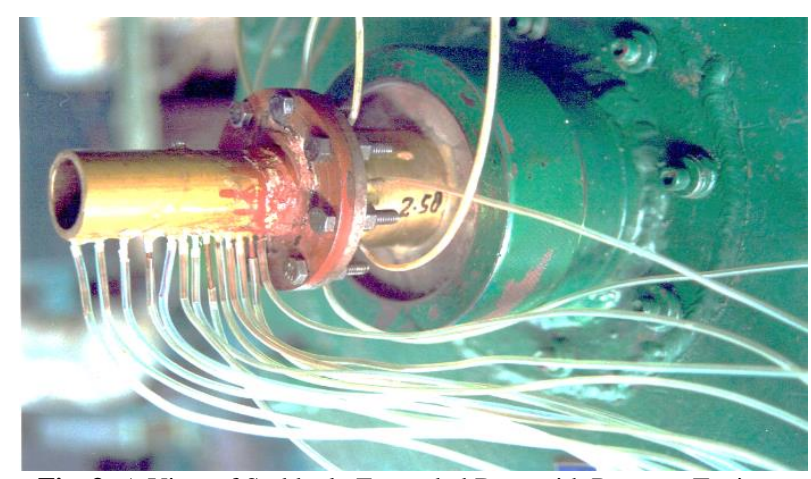

Fig. 3: A View of Suddenly Expanded Duct with Pressure Tapings.

\section{Results and discussion}

The result analysis procedure was followed as in case Ref. [2017]. The dimensionless base pressure as a function of inertia level at various Nozzle Pressure Ratio's and L/D 4, 3, 2 and 1 respectively are presented in figures 4 ((a) to (d)).

\section{Base pressure distribution}

Comparative pattern followed for lower duct length as 4 and 3, as observed from Figs. 4 (a) and 4 (d). The essential distinction among $\mathrm{L} / \mathrm{D}$ less than 4 , the base weight expects extensively higher values at $M=3$. This increase of base pressure turns out to be substantial and tends to wind up noticeably nearly does not dependent of NPR as $\mathrm{L} / \mathrm{D}$ reduces to low values. This is as a matter of concern when the abrupt duct is beneath some restricting value which is indeed needed for the stream to re-join and flow downstream is not available. Due to this phenomena it may lead in non-development of the base vortex which generally will be situated at the base.

Fig. 4 (a) presents results for $\mathrm{L} / \mathrm{D}=4$. It is seen that as long as the flow remains over expanded the base pressure continue to decrease. 
Once the flow has become either correctly expanded or under expanded the base pressure begins to increase and control is most efficient. Similar results are shown in Fig. 4 (b) for $L / D=3$. As for $\mathrm{L} / \mathrm{D}=2$ is concerned, trend sights similarities as of higher L/D's with minimal control effectiveness. Fig 4(d) which is in contrast from results of higher L/Ds.
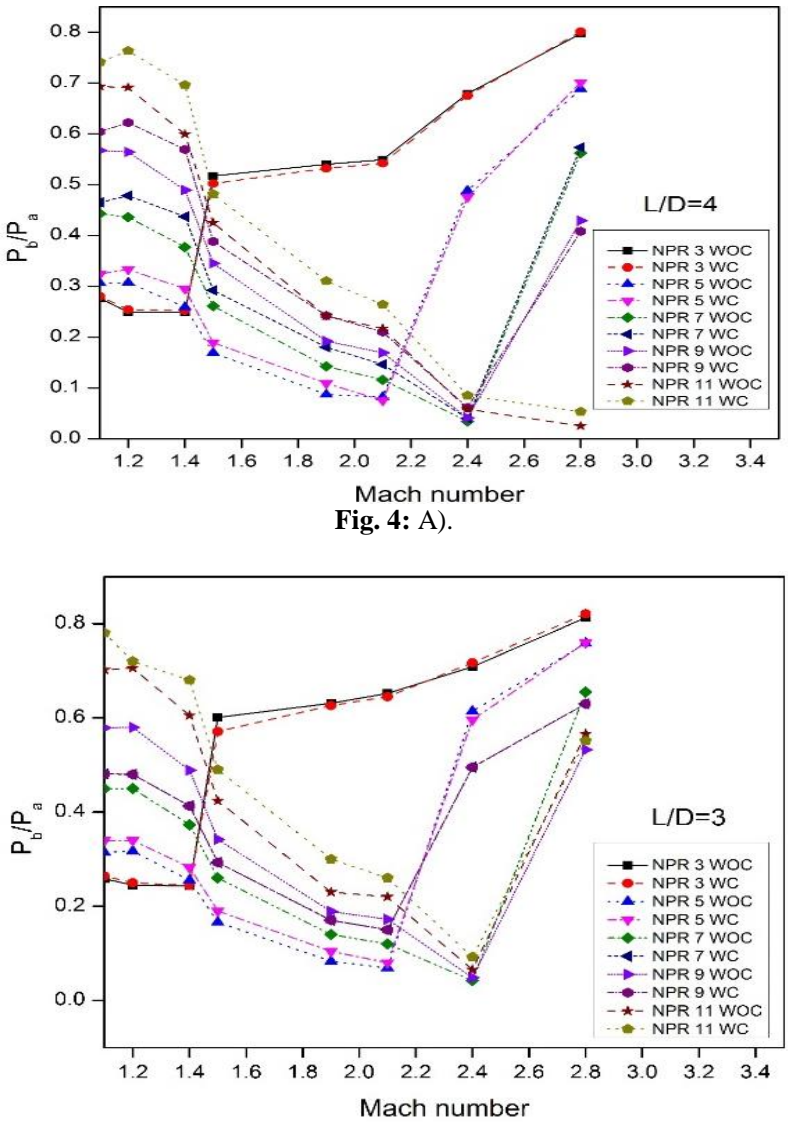

Fig. 4: B).

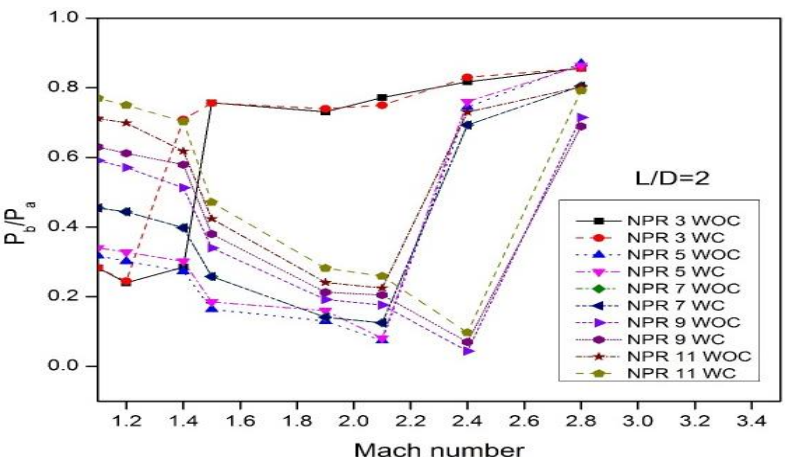

Fig. 4: C)

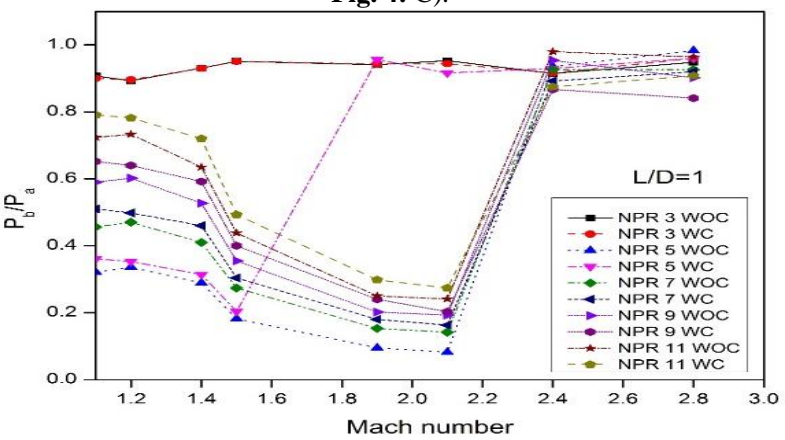

Fig. 4: D)

Fig 4: Base Pressure Distribution at Different Nozzle Pressure Ratio is with and without Micro Jet.

Length to diameter (L/D) proves to be the pivot in achieving control over base pressure with the help of micro jets. Also, reattachment length is the defining factor for base pressure when flow recirculates. The minimum value of this length for sonic and subsonic regimes as proven by Rathakrishnan and Sreekanth (Rathakrishnan \& Sreekanth, 1995) is $\mathrm{L} / \mathrm{D}=[3]$

\section{Wall pressure distribution}

By simulating static pressure across the enlarged duct walls of base flows, a huge challenge came in form of the periodic nature of pressure field. This problem also comes under scanner in this research as study embarks on to investigate how effectively active control techniques can impact wall pressure field. Experimental investigations were done with and without controls to understand this wall pressure distribution and distributions were presented in figures 5 (a) to 6 (h). Analyzing these trends of the outputs, it is conclusive that no significant changes were detected for both with control and without control. Thus implying, active control barely influences wall pressure field distributions to vibrate vigorously. This is a precious advantage as oscillations are one of the major concerns encountered in using control for base pressure fields.

\subsection{Mach number: 1.6}

For Mach number 1.6, Figure 5 (a) to Figure 5 (h) depict the wall pressure distribution as a function of $\mathrm{X} / \mathrm{D}$, flow field is showing oscillatory nature for NPR $=9$ and 11 . These NPRs come under the limit of under-expansion.

For Mach number 1.8, correct expansion occurs at NPR $=6.4$. For low NPRs [3] and [5] we find that the graphs are not showing any oscillatory nature. This may be since these NPRs lie outside the limit of under-expansion. In all graphs, wall static pressure is reaching close to atmospheric pressure at the exit of the enlarged duct. For L/D = [3], at NPR = [7] and [9] micro-jets are effecting the flow field but are not aggravating the oscillations, which is a major advantage of this control. For NPR $=$ [5], wall static pressure reaches atmospheric pressure (which is also the back pressure) very rapidly and remain close to atmospheric for remaining (about 50\%) length of the duct.

The case $\mathrm{L} / \mathrm{D}=[4]$ and NPR $=$ [9] for which maximum base pressure gain is achieved shows no significant effect on the wall pressure field. It is seen that control is reducing the oscillations for this case towards the exit of the duct.

For NPR = [9] and L/D = [2] and three we find that the re-attachment length has increased by applying controls. This is what we are exactly looking for. Increase of re-attachment length is favorable because this will decrease the strength of vortices at the base region. Hence, we can obtain higher pressure at the base. For NPR $=11$ and $\mathrm{L} / \mathrm{D}=[2]$ we again find that re-attachment length has increased by applying controls. For $\mathrm{M}=1.87$ correct expansion occurs at NPR = 6.4. So, when we have low levels of under-expansion, i.e., at NPR $=9$ and 11 , for $\mathrm{L} / \mathrm{D}=$ two then again, we obtain re-attachment point at about $70 \%$ of the length of the enlarged duct.

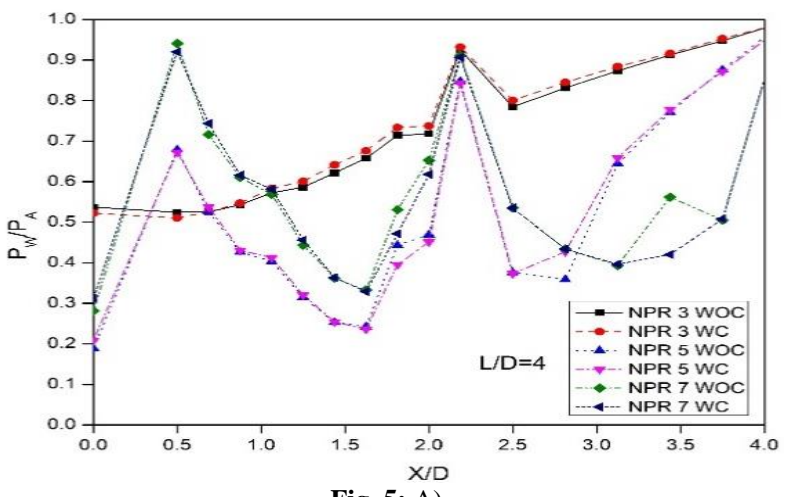

Fig. 5: A) 


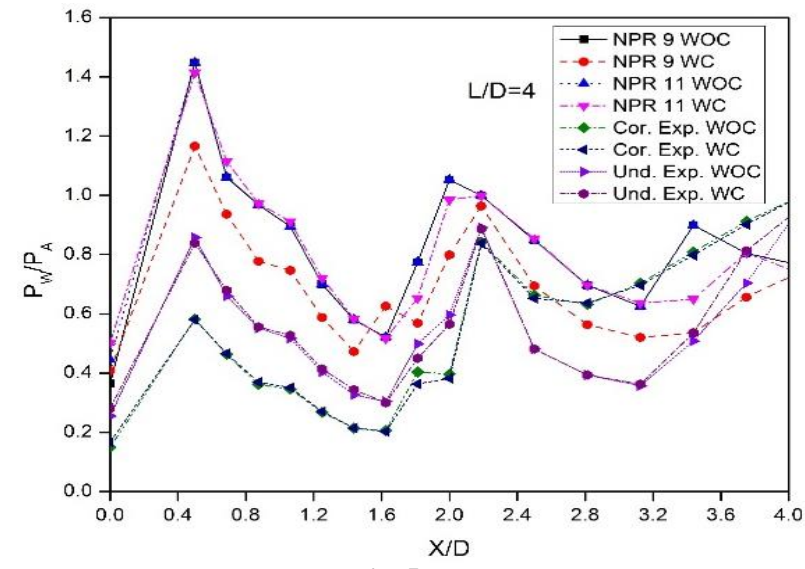

Fig. 5: B).

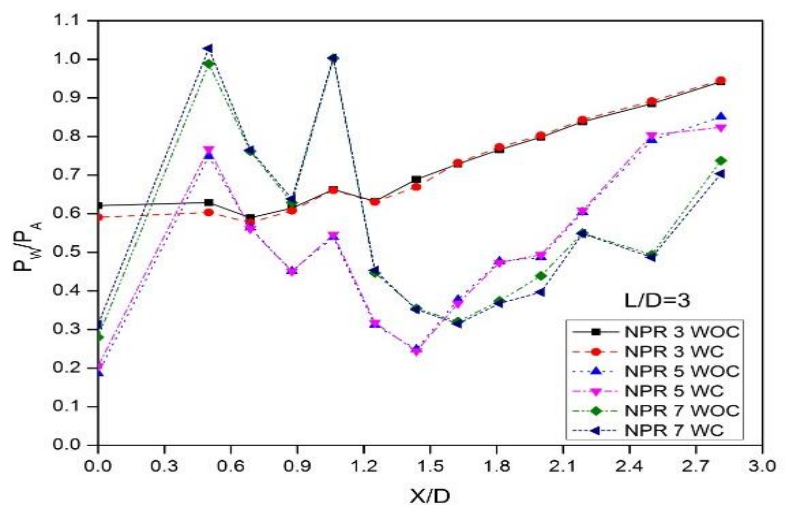

Fig. 5: C).

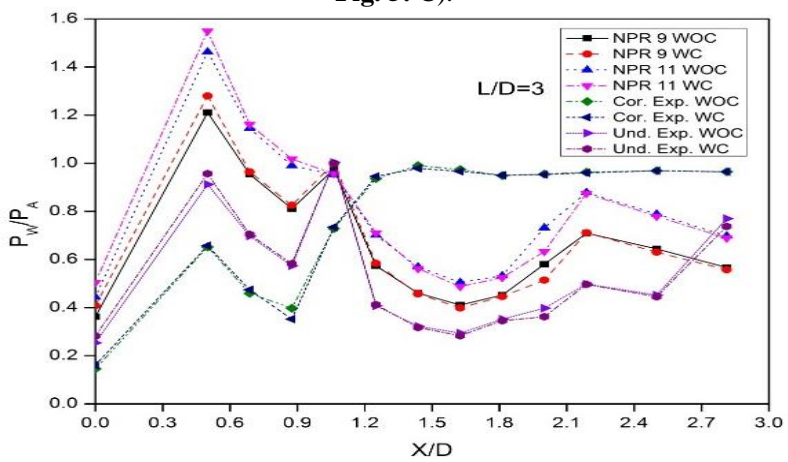

Fig. 5: D).

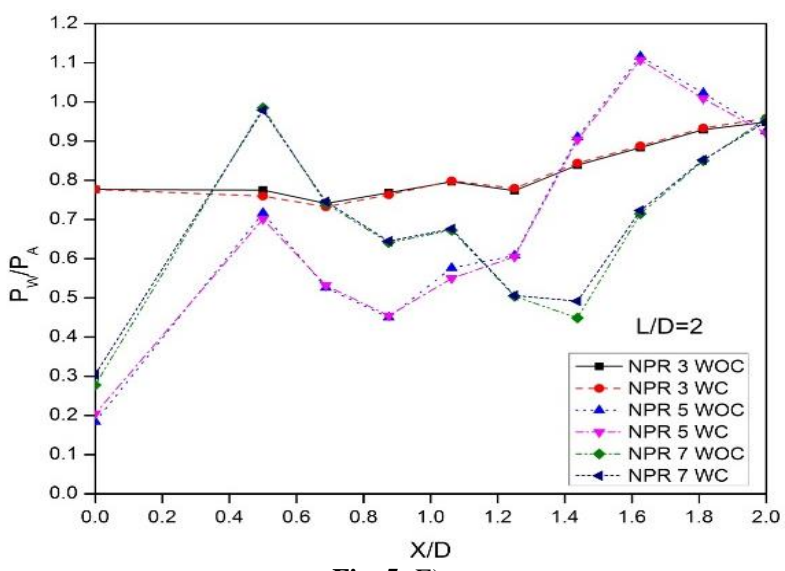

Fig. 5: E).

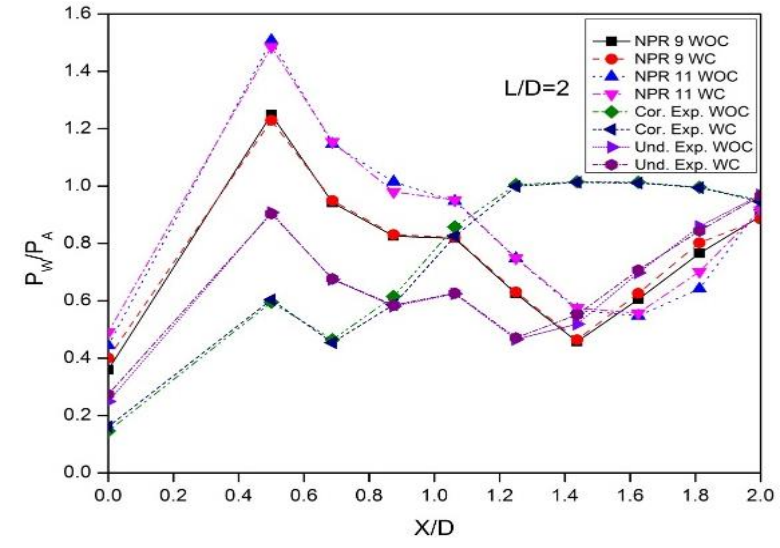

Fig. 5: F)

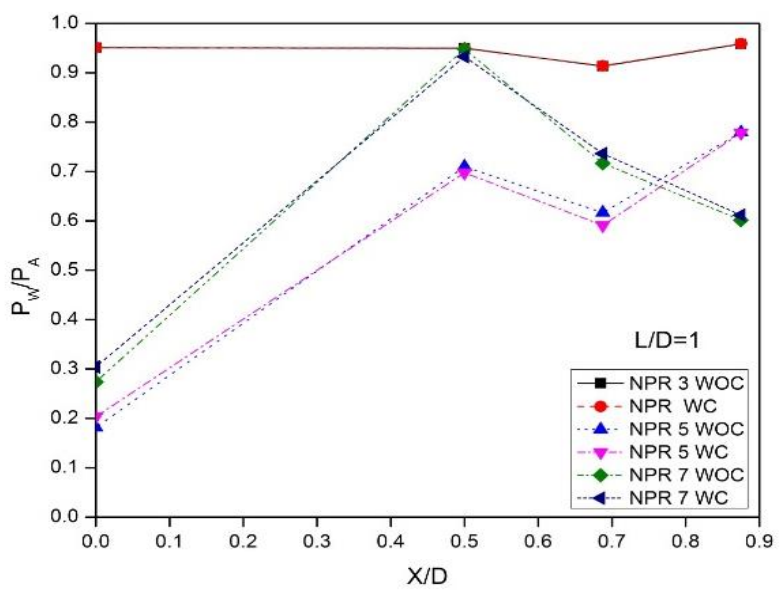

Fig. 5: G).

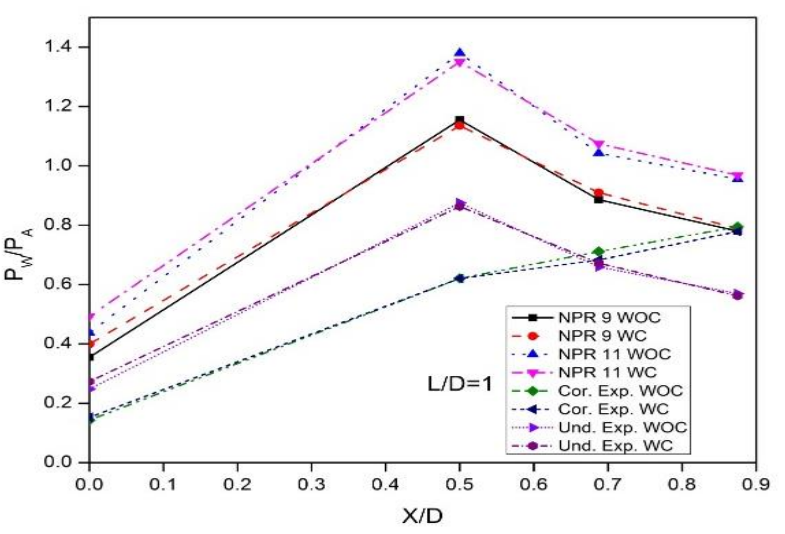

Fig. 5: $\mathrm{H})$

Fig. 5: Wall Pressure Distribution at Mach number with and with Microjet Control.

\subsection{Mach number: 1.8}

For $\mathrm{M}=1.8$, the wall pressure distribution is shown from Figure 6 (a) to 6 (h) respectively. From the observation, it should be noted that the control has got no adverse effect on the static wall pressure flow field. With this it can be taken

that the micro-jets can serve as base pressure controller without imposing any adverse effect in the pressure field in the enlarged duct. Like above mentioned discussion, to quantify the effect of control on wall pressure distribution $\mathrm{Pw} / \mathrm{Pa}$ for the two cases, namely in the presence and absence flow regulation have been observed. It is observed from the results that, for $\mathrm{L} / \mathrm{D}=4$, the control either does not affect the static pressure (as in the case of Figs. 6 (a) and 6 (b). For $\mathrm{L} / \mathrm{D}=3$, at NPR 7 it is seen that, there is some considerable influence of the control taking the wall pressure slightly lower than that for without control in the vicinity of the base region extending up to $\mathrm{X} / \mathrm{D}=4$. 
Similarly, for correctly expanded flow and under expanded flow, this condition is found, the shear layer which is expanding freely from the nozzle is strongly influenced by the oblique shock standing at the nozzle lip. Therefore, flow exiting from the nozzle will tend to deflect in the direction of the shock. Under such circumstances, if micro-jets are activated the entrainment of the micro-jets is bound to carry some mass from the surrounding. This may be the case for the lower wall pressure experienced when the control is on.

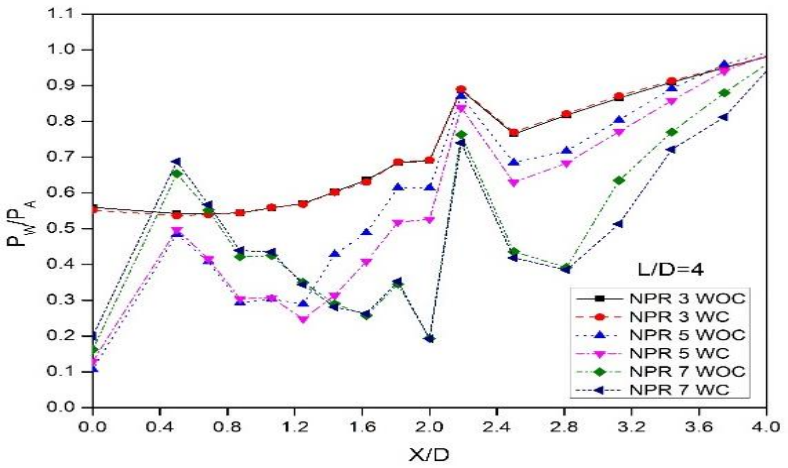

Fig. 6: A).

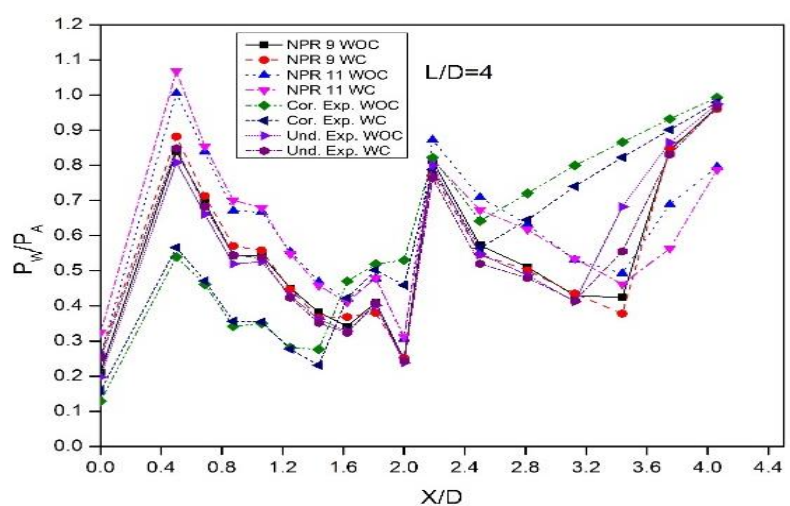

Fig. 6: B).

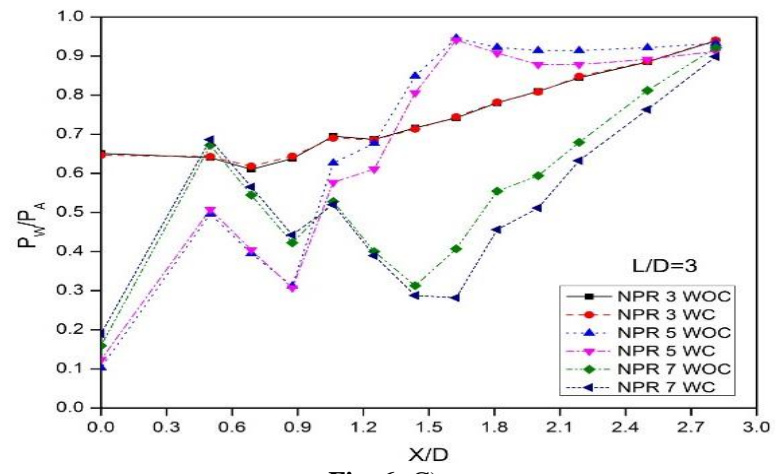

Fig. 6: C).

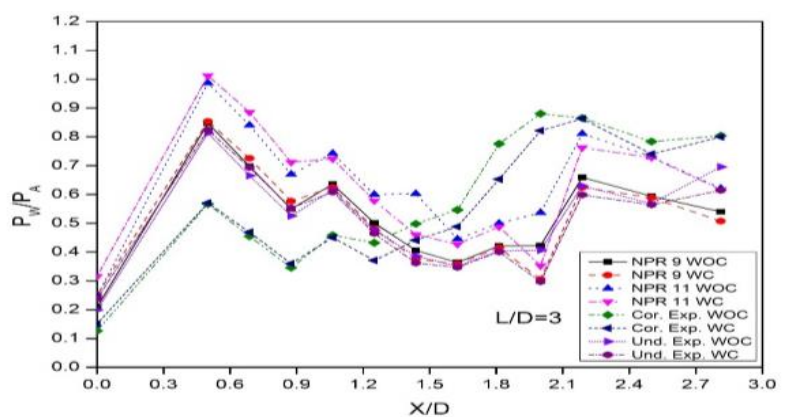

Fig. 6: D).

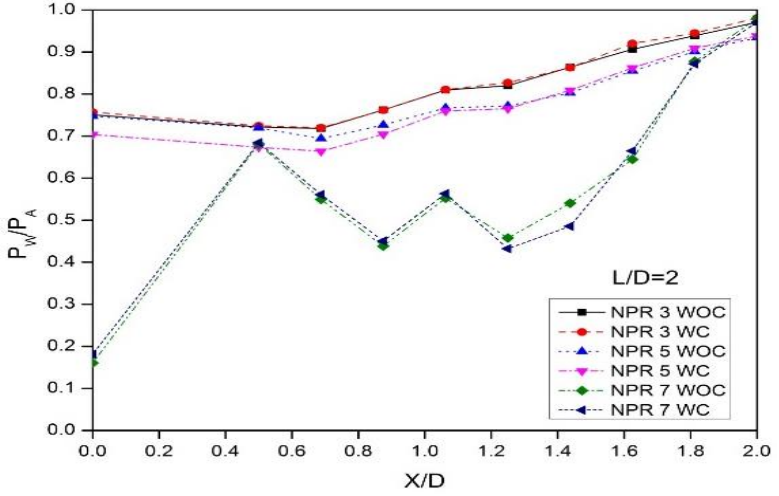

Fig. 6: E).

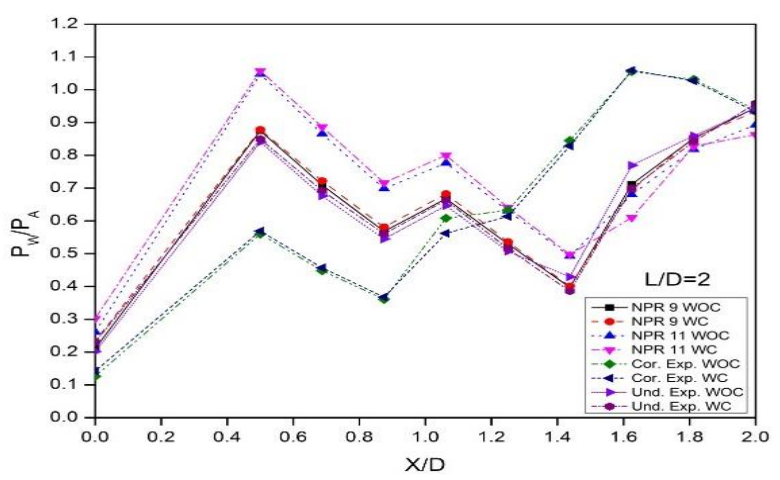

Fig. 6: F)

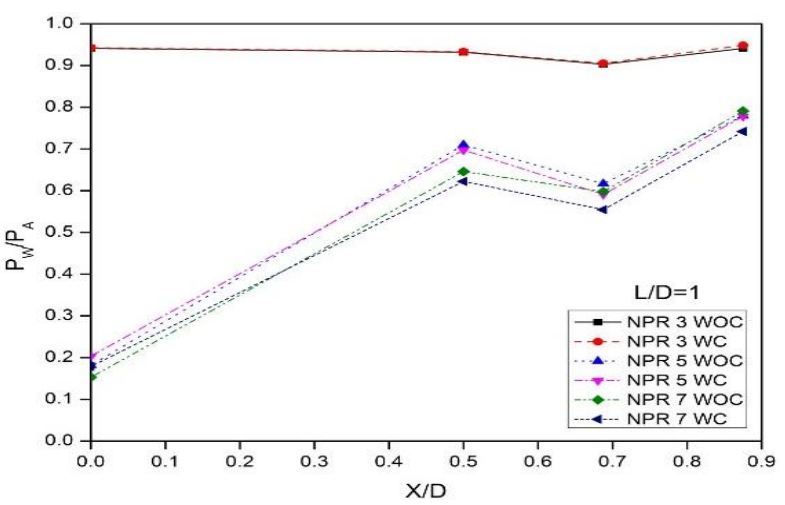

Fig. 6: G)

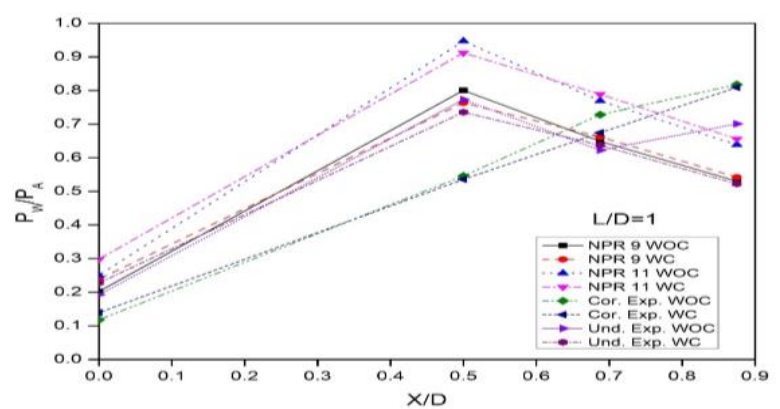

Fig. 6: $\mathrm{H}$ )

Fig. 6: Wall Pressure Distribution at Mach number with and without Micro Jet Control.

For few combination of variables, it is also observed that when the micro jets are activated it results in decrease of base pressure and hence assumes significantly lower values than those without control. A peculiar tone was generated making the jet almost silent and the wall pressures become highly oscillatory for such cases. This is in good agreement with the observation of Anderson and Williams (Anderson \& Williams, 1968) who stated that reduction in noise is associated with the decrement in the pressure at base. The observation of Anderson and Williams has revisited. 
(A)

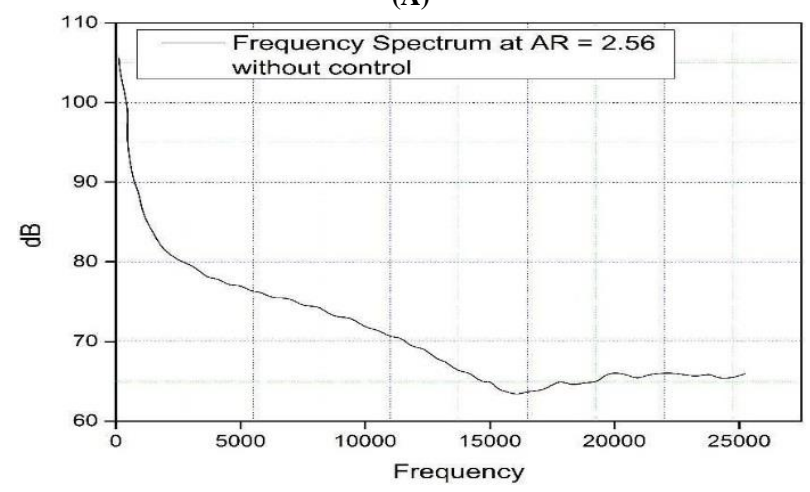

(B)

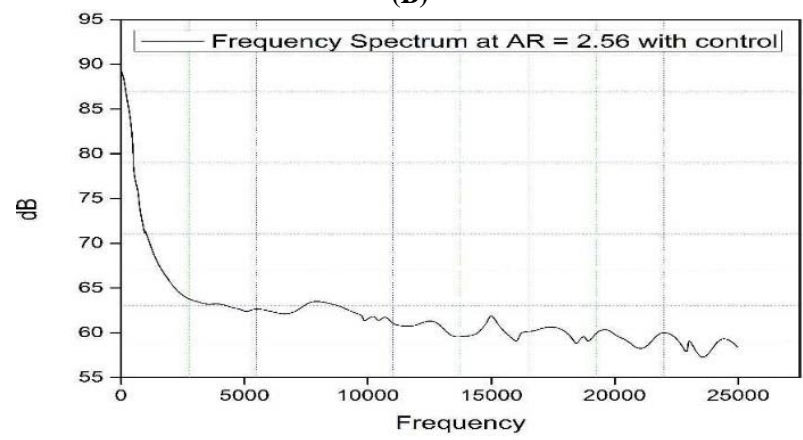

Fig. 7: Frequency Spectrum for Area Ratio $=2.56, \mathrm{~A})$ Without Control at $\mathrm{NPR}=[7], \mathrm{M}=1.8, \mathrm{~L} / \mathrm{D}=10, \mathrm{~B})$ Without Control at $\mathrm{NPR}=[7], \mathrm{M}=1.8$, $\mathrm{L} / \mathrm{D}=10$.

\section{Conclusion}

From the results and discussions of the present experimental investigation the following conclusions can be drawn.

The base pressure is governed by the geometrical parameters viz. the relief of the passage, L/D ratio, nozzle exit inertia level. The $\mathrm{Pe} / \mathrm{Pa}$ influences the separated region. In other words, it can be stated that the NPR, very strongly influences the base pressure. When the micro jets are activated they were found to regulate the flow in the base region, taking the pressure to considerably higher values compared to that for without control for area ratio 2.56 . However, there is certain combination of parameters for which the active control affects negatively.

Base pressure is found to increase with increasing Mach number in the supersonic regime. From the present study, we can the best combination of flow parameters, geometrical parameters to achieve the desired results.

The duct wall pressure distribution, which usually become oscillatory when controls are employed, does not get adversely affected with micro jets. In general duct $\mathrm{L} / \mathrm{D}=3$ appeared to be the limit for base vortex strength manipulation and L/D less than 3 proved to be insufficient for the flow to re-attach in most of the cases

\section{References}

[1] Bashir, M., Baig, M. A. A., Ismail, A. F., \& Khan, S. Control of Suddenly Expanded Flows from Correctly Expanded and under Expanded Nozzles at Supersonic Mach number for Area Ratio 2.56. International Organization of Scientific Research-Journal of Mechanical and Civil Engineering (IOSRJMCE), 76-82.

[2] Brinkhorst, S., von Lavante, E., \& Wendt, G. (2017). Experimental and numerical investigation of the cavitation-induced choked flow in a herschel venturi-tube. Flow Measurement and Instrumentation, 54, 56-67.

[3] Buoni, M., Dietz, D., Aslam, K., \& Subramaniam, V. (2001). Simulation of compressible gas flow in a micronozzle. Paper presented at the Proceedings of the 35th AIAA Thermophysics Conference, AIAA.

[4] Buoni, M., Dietz, D., Aslam, K., \& Subramaniam, V. (2001). Simulation of compressible gas flow in a micronozzle-Effect of walls on shock structure. Paper presented at the 35th AIAA Thermophysics Conference.

[5] Chaudhary, Z. I., Shinde, V. B., Bashir, M., \& Khan, S. A. (2017) Experimental Investigation on the Effectiveness of Active Control Mechanism on Base Pressure at Low Supersonic Mach Numbers Innovative Design and Development Practices in Aerospace and Automotive Engineering (pp. 197-209): Springer.

[6] Chaudhuri, A., \& Hadjadj, A. (2016). Numerical investigations of transient nozzle flow separation. Aerospace Science and Technology, 53, 10-21.

[7] Deprés, D., Reijasse, P., \& Dussauge, J. (2004). Analysis of unsteadiness in afterbody transonic flows. AIAA Journal, 42(12), 2541 2550.

[8] Dutton, J., Herrin, J., Molezzi, M., Mathur, T., \& Smith, K. (1995). Recent progress on high-speed separated base flows. Paper presented at the 33rd Aerospace Sciences Meeting and Exhibit.

[9] Ekanayake, S. (2013). Numerical simulation of a convergent divergent supersonic nozzle flow.

[10] El-Alti, M. (2012). Active Flow Control for Drag Reduction of Heavy Vehicles: Citeseer.

[11] Gamble E., Terrell, D., \& DeFrancesco, R. (2004). Nozzle selection and design criteria. Paper presented at the 40th AIAA/ASME/SAE/ASEE Joint Propulsion Conference and Exhibit.

[12] Hsiung, J.-L., \& Chow, C.-Y. (1995). Computed drag reduction on a projectile using porous surfaces. Journal of Spacecraft and Rockets, 32(3), 450-455.

[13] Hyde, E., Escher, W., \& Roddy, J. (2003). Marquardt's Mach 4.5 supercharged ejector ramjet high-performance aircraft engine project. Paper presented at the 36th AIAA/ASME/SAE/ASEE Joint Propulsion Conference and Exhibit.

[14] Ibrahim, A., \& Filippone, A. (2007). Effect of a Porosity Strength on Drag Reduction of a Transonic Projectile. Journal of Aircraft, 44(1), 310-316.

[15] Ikaza, D. (2000). Thrust vectoring nozzle for modern military aircraft: DTIC Document.

[16] Jahanmiri, M. (2010). Active flow control: a review: Chalmers University of Technology.

[17] Khan, S., Bashir, M., \& Asadullah, M. (2016). An investigation of base flow control by wall pressure analysis in a suddenly expansion nozzle. Journal of Scientific Research and Development.

[18] Khan, S., \& Rathakrishnan, E. (2002). Active control of suddenly expanded flows from overexpanded nozzles. International Journal of Turbo \& Jet-Engines, 19(1), 119-126.

[19] Khan, S. A., \& Rathakrishnan, E. (2004). Active Control of Suddenly Expanded Flow from Under Expanded Nozzles. International Journal of Turbo and Jet Engines,(IJT), 21(4), 233-253.

[20] King, R. (2010). Active Flow Control II: Springer.

[21] Koppenwallner, G., Rammenzweig, D., \& Strunck, V. (1981). Rocket exhaust jet flow and upstream flow field interference. Paper presented at the Experiments and Flow Field Analysis. Congress on Missile Aerodynamics, Trondheim (Norway).

[22] Liang, S.-M., \& Fu, J.-K. (1991). Passive control method for drag reduction for transonic projectiles. Paper presented at the ninth Applied Aerodynamics Conference.

[23] Lipfert, F., \& Fruchtman, I. (1972). Nonuniform flow field generation for supersonic compressor stator development: Design and preliminary results.

[24] Mates, S. P., \& Settles, G. S. (2005). A study of liquid metal atomization using close-coupled nozzles, Part 1: Gas dynamic behavior. Atomization and Sprays, 15(1).

[25] McLellan, J. W. (2006). The effects of diamond injector angles on flow structures at various Mach numbers. Texas A\&M University.

[26] McNally, J., Fernandez, E., Robertson, G., Kumar, R., Taira, K. Alvi, F., Murayama, K. (2015). Drag reduction on a flat-back ground vehicle with active flow control. Journal of Wind Engineering and Industrial Aerodynamics, 145, 292-303.

[27] Mousavi, S. M., \& Roohi, E. (2014). Three-dimensional investigation of the shock train structure in a convergent-divergent nozzle. Acta Astronautica, 105(1), 117-127.

[28] Rathakrishnan, E., \& Sreekanth, A. (1995). Rarefied flow through sudden enlargements. Fluid Dynamics Research, 16(2-3), 131-145.

[29] Sundararaj, M., Yuvaraj, C., Gopinath, S., \& Elangovan, S. (2014). Effect of Rib Geometry on the Base Pressure of Suddenly Expanded Flows. Indian Journal of Science and Technology, 7(S5), 61-63.

[30] Sutton, G. P., \& Biblarz, O. (2016). Rocket propulsion elements: John Wiley \& Sons.

[31] Tripathi, A., Manisankar, C., \& Verma, S. (2015). Control of base pressure for a boat-tailed axisymmetric afterbody via base geometry modifications. Aerospace Science and Technology, 45, 284-293. 
[32] Viswanath, P. (1996). Flow management techniques for base and afterbody drag reduction. Progress in Aerospace Sciences, 32(2-3), 79129.

[33] Washburn, A., Gorton, S., \& Anders, S. (2002). A Snapshot of Active Flow Control Research at NASA Langley. Paper presented at the first Flow Control Conference.

[34] Wu, J., \& New, T. (2017). An investigation on supersonic bevelled nozzle jets. Aerospace Science and Technology, 63, 278-293. 